\title{
Excellence Achievement-Striving in Fighter Pilots on Supersonic Aircraft
}

\author{
Ionela Raluca Maxim
}

President at Psychological Health Center Association, Constanta, Romania

\begin{tabular}{|c|c|}
\hline ARTICLE INFO & ABSTRACT \\
\hline $\begin{array}{l}\text { Keywords: } \\
\text { Achievement-striving } \\
\text { Conscientiousness } \\
\text { Fighter pilots } \\
\text { Performance } \\
\text { Personality traits }\end{array}$ & $\begin{array}{l}\text { The aeronautical profession of fighter pilots on supersonic aircraft is } \\
\text { strongly connected to the motivation, performance and excellence } \\
\text { achievement-striving. The supersonic pilot represents the highest and } \\
\text { most desirable position in the air force. Research showed that their } \\
\text { selection is made by choosing the potential elite candidates after } \\
\text { testing the physical, mental abilities and personality traits specific to } \\
\text { this profession. The present research examined the personality trait } \\
\text { of conscientiousness with achievement-striving facet in fighter pilots } \\
\text { on supersonic aircrafts, by using the "IPIP NEO" (International } \\
\text { Personality Item Pool NEO) based on Big Five by comparison of two } \\
\text { groups, one of fighter pilots on supersonic aircraft and one of non- } \\
\text { pilots. The results indicated that fighter pilots on supersonic aircraft } \\
\text { have higher level of excellence achievement striving in their } \\
\text { performance, they tend to be more competitive to become the best } \\
\text { and the desire for victory is needed in their highly risky air missions. }\end{array}$ \\
\hline
\end{tabular}

\section{Introduction}

Studies suggest that personality traits of fighter pilots interact with flying performance, contribution in this way to different accidents. The profession of fighter pilots is one of the most tested one. Personality traits of those individuals who perform this profession are very important in the selection process. Qualities such as achievement motivation and ability to make decisions and act quickly, in addition to emotional stability, have been seen as particularly important in military or fighter pilots (Carretta et al. 1996).

The assessment of personality traits plays a decisive role in the selection of fighter pilots. The possible failures represent a big loss for the national Air Forces having in view that the costs of fighter pilots trainings are very high. It is required for those organizations to have a costeffective system of selection and training (Lambirth T. et al. 2003).

The most important dimension based on Big five personality traits (neuroticism, extraversion, openness to experience, agreeableness and (conscientiousness) that is acknowledged as predictor of performance in this profession is conscientiousness (Siem\&Murray 1994).

The evaluation and selection of individuals for the profession of supersonic fighter pilots aims to maximize their skills, abilities and training. The supersonic fighter pilot needs a strong intrinsic motivation considering the professional life chosen, the requirements of the military condition and the complexity of the situations to be overcome (Pitariu\&Sîntion, 2003).

\subsection{Concepts of excellence achievement striving and motivation}

The achievement-striving can be described as a personality trait that implies the desire for success and high aspirations. Moreover, it is an element that underlines the level at which an individual seeks to achieve its objectives and purposes, regardless of the effort they need to make. Individuals have desires for achievement-striving that depend on how seriously they

* Corresponding Author E-Mail Address: ralucamaxim30@gmail.com 
take their work and how active they are for the difficult, stressful and risky work (Bluen et al., 1990).

The conscientiousness factors comprises the facet of achievement-striving that reflects high levels of aspiration, self-focus, devotion to work and energy that are important in personal and professional goals (Costa and McCrae, 1992).

The concept of achievement-striving and success can be connected by social dominance through leadership, much focused attention and relates very well with extraversion and conscientiousness (Watson and Clark, 1997).

Achievement-striving and conscientiousness are necessary and beneficial in increasing the level of performance because they can be related with certain attitudinal tendencies, such as organization, determination, perseverance and responsibility (Furnham et al., 2004).

The professional success can be achieved if individuals set standards that they can meet with the skills compatible with the respective profession, with the related effort and result satisfaction, by eliminating exaggerated perfectionism (Enns et al., 2002).

Motivation is one of the personality factors that is the basis of the search of the achievement of superior performance in a professional field. Motivation determines the behavior of adaptation or maladaptation to the environment (Enache, R. et al., 2011).

"Motivation is an important lever in the process of self-regulation, a driving force of all individual psychic and human development. The motivation instigates drives and triggers the action and directs it to the goal, by allowing the activity to be prolonged if the goal has not been reached." (Zlate, M., 2006).

The achievement-striving in the individual can also be connected voluntarily. The will can be defined as a determined desire that involves the individual in action. The volitional effort mobilizes the individual to act according to the size of the obstacles that may appear on the path to success (Zlate, M., 2006).

The level of aspiration and achievement comprises a motivational-volitional element that mobilizes individuals to make the effort to reach the objective, but also cognitive-evaluative with which the individual sets his targets according to the results obtained previously (Pitariu\&Sîntion, 2003).

Individuals who have skills and aptitudes in a field need a rising motivational level and not constantly in order to not stagnate but to increase its performance. The established motivations should not exceed much their own capacities and possibilities (Pitariu \& Sîntion, 2003).

The success is connected with the performance, and the achievement of the performance engages the individual with the personality factors, the motivational, volitional, cognitive and aptitude elements but also the professional or educational environment. These components guide and direct the individual to seek success and to wish for their performance at the highest level in the respective field (Watson \& Clark, 1997).

Picano et al. (2006) underlines the importance of initiative, motivation, and drive for individuals pursuing a career in high-risk operational positions, such as supersonic fighter pilots.

\section{Research methodology on achievement-striving in fighter pilots}

\subsection{Purpose}

The present research seeks to provide current normative data by comparing the excellence achievement-striving personality characteristic based on IPIP Neo questionnaire (based on Big 5 test) of supersonic-aircraft fighter pilots to general population.

\subsection{Participants}

This research was created with the participations of one sample of supersonic fighter pilots and one sample on non-pilots from Romania country. The information and data were collected from 30 male supersonic fighter pilots, aged between 25 and 45 years, and 30 non-pilots (the sample 
consisting of 30 male persons active in the labor market), aged between 25 and 45 years. The figure 1 presents the two samples used for this comparative research paper.

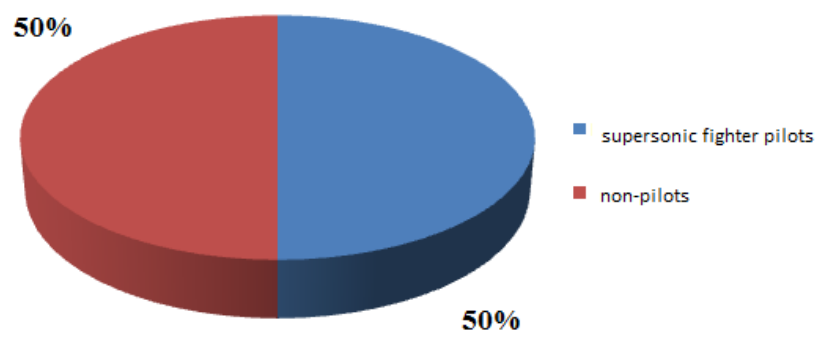

Figure 1. Distribution of participants in two samples

\subsection{Research hypothesis}

The objective of this paper is to verify the hypothesis that the supersonic fighter-pilots manifest a higher achievement-striving by overcoming their human nature in comparison to non-pilots.

\subsection{Instruments}

The scores of achievement-striving variables, that is facet of conscientiousness factor of IPIP NEO questionnaire, were used for the analysis of this hypothesis in order to compare the two samples of supersonic fighter pilots and non-pilots.

\subsubsection{NEO International Personality Item Pool (IPIP)}

The NEO International Personality Item Pool (IPIP) questionnaire is a personality test that is created based on the Big Five model (Goldberg, 1999).

This questionnaire was used based upon a review of the literature and the conclusion that it is useful because it focuses on general domains of personality by presenting the relation between individual personality traits and profession characteristics.

This questionnaire IPIP NEO has 5 dimensions (N, E, O, A, C) with 6 facets each. Each facet has 10 items that have been translated and adapted in Romanian language. IPIP NEO instrument has the following facets:

1. The Neuroticism factor (N) contains 6 facets: N1: Anxiety, N2: Anger, N3: Depression, N4: Selfconsciousness, N5: Immoderation, N6: Vulnerability.

2. The Extraversion factor (E) contains 6 facets: E1: Friendliness, E2: Gregarious spirit, E3: Assertiveness, E4: Activity level, E5: Excitement-seeking, E6: Cheerfulness.

3. The Openness to Experiences factor $(\mathrm{O})$ contains 6 facets: O1: Imagination, O2: Artistic interest, O3: Emotionality, O4: Adventure spirit, O5: Intellect, O6: Liberalism.

4. The Acceptability factor (A) contains 6 facets: A1: Trust, A2: Morality, A3: Altruism, A4: Cooperation, A5: Modesty, A6: Sympathy / Compassion.

5. Conscientiousness factor (C) contains 6 facets: C1: Self-efficacy, C2: Orderliness/ Discipline, C3: Dutifulness, C4: Achievement-striving, C5: Self-discipline, C6: Cautiousness.

\subsection{Procedure}

The IPIP NEO questionnaires were distributed to the samples of fighter pilots and non-pilots in paper-pencil format, in Romanian language.

\subsection{Data analysis}

Differences between fighter-pilots and non-pilots participants in achievement-striving levels were analyzed by using IBM SPSS Statistics. The distribution of the variable for both samples 
of participants was verified with Kolmogorov-Smirnov test. The comparison was made by using T-test for independent samples.

\section{Findings}

The scores obtained from the IPIP NEO questionnaires from both samples were used in IBM SPSS Statistics.

Table 1 contains the central tendency obtained for the two samples, pilots $\mathrm{N}=30$, mean 40.5 , median 40.5 and standard deviation 3.23, and non-pilots $\mathrm{N}=30$, mean 38.8, median 38.5 and standard deviation 3.07.

Table 1.

Central tendency (average values) of the numerical data set related to achievement-striving variable

\begin{tabular}{lccc}
\hline & \multicolumn{2}{c}{ Statistics } \\
\cline { 3 - 4 } & & $\begin{array}{c}\text { Achievement-striving in } \\
\text { fighter pilots }\end{array}$ & $\begin{array}{c}\text { Achievement-striving in } \\
\text { non-pilots }\end{array}$ \\
\hline $\mathrm{N}$ & Valid & 30 & 30 \\
Mean & Missing & 0 & 0 \\
Median & 40.5667 & 38.8000 \\
Mode & 40.5000 & 38.5000 \\
Std. Deviation & 41.00 & $38.00^{\mathrm{a}}$ \\
\hline
\end{tabular}

The distribution of the achievement-striving variable in the two samples was verified by confirming the normality of the distribution by the Kolmogorov-Smirnov test, according to Table 2 in this paper.

Table 2.

Distribution of the achievement-striving variable in the two samples

Tests of Normality Kolmogorov-Smirnov ${ }^{\mathrm{a}}$

Achievement-striving-pilots

\begin{tabular}{ccc}
\hline Statistic & df & Sig. \\
\hline .164 & 30 & .039 \\
.294 & 30 & .000 \\
\hline
\end{tabular}

Tables 3 presents the comparison for which it was used the $\mathrm{T}$ test with independent samples, in which Sig. (2-tailed) value is 0.035 that is less than 0.05 and that explain that the variability in the two conditions means is significantly and statistically different, by resulting in a significant difference between the two samples in achievement-striving variable.

Table 3.

Results in comparison with T-test independent samples for achievement-striving variable

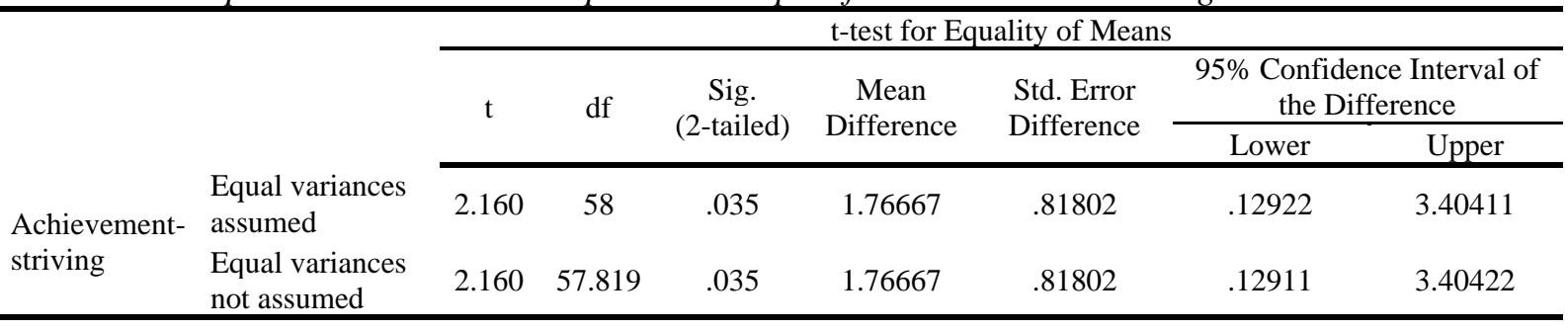

\section{Discussion}

The hypothesis is confirmed, resulting that the fighter pilots have a higher desire for excellence achievement-striving in comparison to the general population. 
The fighter pilots on supersonic aircraft have high motivational levels and make every psychically, intellectually and physically effort to perform in their professional duties. This personality trait is not developed by the military environment in which these pilots are professionally trained, but exists as a stable personality attribute to all those who choose this profession of supersonic aircraft flying.

Motivation is what guides the pursuit of success with all the forces and powers of these fighter pilots. The fighter pilots have an attitude of overflowing perseverance that implies the desire to fly, the intensity and direction of this motivation with flight safety.

Fighter pilots on supersonic aircraft adapt to the aeronautical environment based on flight motivation, ability to fly but also emotional stability, elements that can be identified even before being declared fit for this profession.

Fighter pilots are looking for excellence achievement-striving with performance orientation. They tend to be competitive in order to become the best, and the desire for victory is necessary to obtain as many points as possible in the highly risky air missions.

The job satisfaction motivates a supersonic fighter pilot to make more effort and encourages them to perform better or get performance excellence. Appreciation from colleagues and superiors is another element that accentuates the desire for success.

Individuals who perform this profession simply love to fly on supersonic aircraft and recognize the real danger they face and the demands during flight training, having the ability to turn aggressive forces into extremely well calculated risks management and assumption.

There are some aspects that should be noted but are classified by Romanian Air Force department, which are related to the motivation for success and the achievement-striving, namely the number of hours flown during a pilot's career, performance on flight exercises, briefing and debriefing standards, artillery tactics, flight discipline and flight safety. These elements would present a considerable evolution in the supersonic fighter pilot profession and the reach of maximum performance based on the excellence achievement-striving.

\section{Conclusions}

This paper showed that fighter pilots on supersonic aircraft have higher level of excellence achievement striving in their performance in comparison to general population. The level of achievement-striving facet of conscientiousness dimension of IPIP NEO can be used in fighter pilots testing or selection.

The results of the current study show that Romanian supersonic fighter pilots have superior achievement-striving and conscientiousness as compared to general population and may prove to be essential to psychologists working in the evaluation of Romanian fighter pilots.

The personality of supersonic pilots is complex and specific, with an impact on their professional success. The supersonic fighter pilots are very intrinsically motivated and very determined to constantly study and perform as well as possible. They can undertake and complete tasks regardless of the level of difficulty.

Another future comparison may be focused on the differences between male and female supersonic fighter pilots. There are currently no such comparative gender studies in the fighter pilot profession on supersonic aircraft, due to the small number of women, but it would be very interesting to identify personality differences.

\section{Acknowledgment}

The realization of this paper was made with the important contribution of supersonic aircraft fighter pilots of the Romanian Air Force. Special thanks to all fighter-pilots and non-pilots participants who contributed to this research. Other special thanks to my Professor PhD. Filaret Sintion from Ovidius University, Constanta, Romania who offered me his guidance for my study on aeronautical and military psychology. 


\section{References}

Bluen, S. D., Barling, J., \& Burns, W. (1990). Predicting sales performance, job satisfaction, and depression by using the achievement strivings and impatience-irritability dimensions of type A behavior. Journal of Applied Psychology, pp. 75(2).

Carreta, T.R. \& Ree, M. J. (2000). Pilot selection methods. Crew System Interface Division, pp. 2

Costa, P. T., \& McCrae, R. R. (1992). Multiple uses for longitudinal personality data. European Journal of Personality, pp. 6.

Enache, R., Dragu, A., Giurgiu, L., (2011), General psychology with applications in the practice of social assistance, Ovidius University Press, Constanta, pp. 10.

Furnham, A., \& Chamorro-Premuzic, T. (2004). Personality and intelligence as predictors of statistics examination grades. Personality and Individual Differences, pp. (37) 5.

Goldberg L.R. (1999). Mervielde, I. and Deary, I. and De Fruyt, F. and Ostendorf, F.(eds.).“A broad-bandwidth, public domain, personality inventory measuring the lower-level facets of several five-factor models" (PDF). Personality psychology in Europe. 7: 7-28.

Lambirth TT, Dolgin DDL, Rentmeister-Bryant HK, Moore JL.(2003) Selected personality characteristics of student naval aviators and student naval flight officers. Int J Aviat Psychology 13 (4): pp. 415-27.

Picano, J. J., Williams, T. J, \& Roland, R. R. (2006). Assessment and selection of high-risk operational personnel. In C. H. Kennedy \& E. A. Zillmer (Eds.), Military Psychology, New York, NY: Guilford, pp. 353-370.

Pitariu H \& Sintion F., (2003), Psychology of the fighter, Bucharest: Military Publishing House; pp. 8.

Siem FM, Murray MW. (1994) Personality factors affecting pilot combat performance: a preliminary investigation. Aviat Space Environ Med; 65 (5, Suppl.) pp. A45-48.

Sintion, F., Calin M. F. (2012), Research methodology in psychology, Ovidius University Publishing House, Constanta, Romania.

Watson, D., \& Clark, L. A. (1997). Extraversion and its positive emotional core. In R. Hogan, J. Johnson, \& S. Briggs (Eds.), Handbook of personality psychology. San Diego, CA: Academic Press; pp. 767-793.

Zlate, M., (2006), Fundamentals of psychology, University Publishing House, Bucharest, pp. 151-166. 